\title{
The Influence of Parental Concern on Food Companies' Marketing Strategies
}

\author{
Mamoru Miyamoto ${ }^{1}$ \\ ${ }^{1}$ Department of Economics, Kanto Gakuin University, Yokohama, Japan \\ Correspondence: Mamoru Miyamoto, 1-50-1 Mutsuurahigashi, Kanazawa-ku, Yokohama, Japan. Tel: \\ 81-45-781-2001. E-mail: miya@kanto-gakuin.ac.jp
}

Received: November 24, 2014

Accepted: December 11, 2014 Online Published: January 26, 2015

doi:10.5539/ijms.v7n1p 15

URL: http://dx.doi.org/10.5539/ijms.v7n1p15

\begin{abstract}
Consumer socialization has been investigated in the literature of various fields, including consumer behavior, marketing strategy, advertising, law, child education, medicine, and nutrition. While the importance of consumer socialization in the study of economics may be self-evident, there are few academic contributions on the topic. Thus, using orthodox microeconomic theory, in particular, game theory, we aim to analyze the interaction between parents as consumer socialization agents and food companies advertising to children through media (e.g., television commercials).

This paper emphasizes that parental concern, or parental style, has a significant effect on food companies' marketing strategies toward children as well as on children's consumer socialization. From a game theoretical perspective, we find that the marketing behaviors of food companies are greatly influenced by the extent of parental concern for consumer socialization. In contrast, we find that parents do not alter their behaviors based on their awareness of the importance to food companies of their parental concern for consumer socialization. This paper asserts that parents, as agents, should consider how the volume of advertisements food companies supply is affected by the extent of parental concern for consumer socialization.
\end{abstract}

Keywords: advertising, children, consumer socialization, marketing, parental concern, parental style

\section{Introduction}

Ward (1974) defines consumer socialization as the process "by which young people acquire the skills, knowledge, and attitude relevant to their functioning as consumers in the market place" (p. 2). Consumer socialization occurs primarily through media, parents, and peers (Ahmad, Sidin, \& Omar, 2011; Carruth \& Skinner, 2001; Moschis, 1985; Özmete, 2009). This paper focuses specifically on parents as consumer socialization agents, as they are considered to have the most significant effect on children's decision making (McNeal, 1992). Indeed, they are "the primary gatekeepers to children's food intake" (Buijzen, 2009). Although we focus on parents in this study, we acknowledge that both media (e.g., newspapers and the Internet) and peers play an important role in consumer socialization (Ahmad et al., 2011).

This paper introduces a simple economic model that characterizes the interaction between parents as agents and food companies under a game theoretical context. In other words, each player reacts to the other's decision making. The significance of the role of parents in consumer socialization has been stressed from the perspective of parent-child relation, parent-child interaction, and family communication, among others (e.g., Carlson, Grossbart, \& Stuenkel, 1992; Fisher, \& Birch, 2007; Moschis, 1985; Özmete, 2009; Rose, 1999; Rose, Dalakas, \& Kropp, 2003; Savage, Fisher, \& Birch, 2007; Scaglioni, Arrizza, Vecchi, \& Tedeschi, 2011). However, few researchers have explored the interaction between parents and food companies in the consumer decision making process. This may be due to the fact that food companies express their messages through media, not to specific customers but to customers in general. Nonetheless, it is safe to presume that food companies aim to identify the attributes of their customers, especially parents' behaviors as agents. Accordingly, food companies' marketing strategies are greatly influenced by parental concern and, more specifically, the extent to which parents are conscious of consumer socialization of children.

Our model considers compensation for marketing-related diseases, such as obesity and diabetes, in children. Food companies are assumed to compensate perfectly for such diseases, and partial compensation is given for 
diseases in children who make decisions independently without the influence of food marketing. Food and beverage companies, as well as the tobacco industry, tend toward self-regulation in order to evade the imposition of enormous penalties. Although the Federal Trade Commission (FTC) demanded self-regulation, this approach has proven to be ineffective (Pomeranz, 2010).

It is noteworthy that our results, including the two lemmas detailed in Section 3, are based on assumptions that may seem strange, but have become popular in economics. This article is organized as follows. Section 2 derives our simple model. Section 3 explores an interaction between parents as agents and a food company advertising to children. Finally, we present our concluding remarks in Section 4.

\section{Model}

\subsection{Basic Framework}

We assume a two-period model, where consumers' time horizon is divided into a childhood period and an adulthood period. During the former period, "period 1", consumers spend their childhood with their parents, encountering various types of food industry commercialization aimed at children. During the adulthood period, "period 2", consumers become less concerned with foods and food advertisements. Therefore, during period 1, food manufacturers invest significant advertising resources into children as their main targets via mass media, such as television and the Internet.

It is significant to note that children do not necessarily display the same consumer behaviors that adults do. Children are highly impressionable to the marketing strategies of food companies; therefore, children's demand for food products may depend on the amount of advertising food companies deliver, which is largely done through television commercials. The FTC estimates that " $\$ 1.6$ billion was spent in 2006 on food marketing and promotion directed at children and adolescents, of which $\$ 745$ million was for television advertising" (Wilde, 2009, p. 156).

Thus, we use $x$ to denote the amount of advertisement a food company actually delivers at the beginning of period 1. $x$ denotes the number of television commercials during each period. As children have not yet completed their consumer socialization, their demand for food products will depend on the amount of advertisement a food company provides through television commercials. The demand function of children for food products is written as follows:

$$
D=D(x)
$$

where $D(x)$ is differentiable and strictly concave; that is,

$$
D^{\prime}(x) \equiv \frac{\partial D}{\partial x}>0, \quad D^{\prime \prime}(x) \equiv \frac{\partial^{2} D}{\partial x^{2}}<0 .
$$

Alternatively, the demand irrelevant to $x$ is written as $\widetilde{D}(>0)$, which, as described later, is independent of the food company's advertising strategy.

Wilde (2009) emphasizes that increased marketing of food products leads to a brand-switching effect and a demand-expanding effect. In our model, we consider only the latter effect; if the brand-switching effect is considered more significant, food companies would welcome regulation in food advertising, as such interference would help them retain customers and reduce advertising costs (Wilde, 2009). We focus only on the amount of television commercials, without considering the content and quality level of those commercials. Nevertheless, the content and quality of commercials have been recognized as important aspects of marketing strategies.

$C$ denotes the marketing costs a food company incurs as a result of creating and distributing television commercials. It is apparent that these costs depend on the amount of commercials $x$, and $C$ is an increasing function of $x$. Thus,

$$
C=C(x)
$$

where $C(x)$ is differentiable and strictly convex; that is,

$$
C^{\prime}(x)>0, \quad C^{\prime \prime}(x)>0 .
$$

For convenience, all costs other than the marketing costs a food company incurs are assumed to be constant $(\bar{C})$.

Let $\alpha(0 \leq \alpha \leq 1)$ be the probability that during period 2, consumers will suffer significant physical consequences, such as obesity or diabetes, unless they alter their unhealthy eating habits and avoid the influence of food product television commercials. Let $1-\alpha$ be the probability in the absence of any unhealthy consequence. Because probability $\alpha$ coincides with the extent to which consumers comply with food marketing 
strategies, $\alpha$ ultimately depends on $x$, the amount of television commercials encountered. Thus,

$$
\alpha=\alpha(x)
$$

where

$$
\alpha^{\prime}(x)>0, \quad \alpha^{\prime \prime}(x)<0
$$

\subsection{Parents as Consumer Socialization Agents}

A number of studies have shown that parents play a significant role in consumer socialization. As agents, parents transmit to their children a wide variety of properties necessary for socialization, such as norms, attitudes, motivations, and behaviors (Ahmad et al., 2011; Carlson \& Grossbart, 1988; Moschis, 1985; Savage, 2007; Scaglioni et al., 2011). In our framework, at the beginning of period 1, parents as agents initiate consumer socialization of children. The way parents relate to their children's consumption affects socialization outcomes. Children whose parents put much effort into consumer socialization will perform rationally in their consumption decision making without being affected by food companies' advertisements. On the other hand, children with parents who are entirely unaware of their role in consumer socialization will be susceptible to food companies' marketing strategies.

We model such consumer socialization outcomes by $\theta(0<\theta<1)$. In other words, $\theta$ measures the extent to which children are unaffected by food companies' television commercials as a result of parental engagement in consumer socialization during period 1 . Therefore, the greater $\theta$ is, the less children are affected by food companies' television commercials. As there might be some controversy concerning what should evaluated as socialization outcomes, we embody our perspective by constructing the mathematical model.

Solomon (2004) classifies parents, as consumer socialization agents, into three different styles; "authoritarian parent," "neglecting parent," and "indulgent parent" (Carlson et al., 1988; Özmete, 2009). For the purpose of mathematical convenience, we assume these styles to be continuous and express them as $\tau(>0)$. Note that the classification is not necessarily continuous and it is only for the mathematical convenience. $\tau$ denotes the extent to which parents are consciously involved in consumer socialization of children. In other words, it reflects the degree of agency parents assume regarding children. Parental style or parental concern is a key category in our framework. We suppose that $\tau$ determines the level of consumer socialization outcomes $\theta$. Thus,

$$
\theta=\theta(\tau)(0<\theta<1, \tau>0)
$$

where

$$
\theta^{\prime}(\tau)>0, \quad \theta^{\prime \prime}(\tau)<0
$$

The greater is $\tau$, an indicator of parental concern regarding consumer socialization, the higher is the level of consumer socialization outcomes $\theta$. A deeper parental concern leads to improved consumer socialization outcomes and, thus, an increased likelihood that children display rational economic behavior. We employ the concept of economic rationality consistent with its extensive use in economic literature (see, e.g., Kreps, 1990). In this context, it means that children maximize the difference between their willingness to pay (WTP) for food consumption and the costs they incur as a result of that consumption. While this assumption may be debatable, we assert that it effectively clarifies the nature of children's economic decision making behaviors.

Even when parents are fully engaged in consumer socialization of children, a child may not necessarily develop rational economic behavior. As is easily imagined, children can still be partially affected by food companies' commercial advertisements. Thus, with proportion $\theta(\tau)$, children follow the maximization behavior, and with proportion $1-\theta(\tau)$, they follow the behavior encouraged by a marketing strategy. Therefore, the value of $\theta(\tau)$ is neither zero nor one. The children of parents who are eagerly engaged in consumer socialization still cannot fully overcome the influence of companies' marketing.

\subsection{Compensation for Marketing-Related Diseases}

The threat of an increase in marketing-related diseases, such as obesity and diabetes, in children is currently escalating through the world. Many children are victims of such diseases, being forced to live in a toxic commercial environment (Amano, 2014; Linn, 2004; Schor, 2004). The World Health Organization demanded social accountability on the part of food and beverage companies selling products that have a negative impact on children's health (Amano, 2014).

Our model presumes that a food company compensates perfectly for marketing-related diseases that result from the harmful influence of television commercials on children. Partial compensation is given for diseases affecting children who make their decisions independently, without any influence of television commercials. In the latter 
case, let $\gamma(0<\gamma<1)$ be a ratio of the responsibility the food company must take for the diseases. The ratio $\gamma$ is assumed based on a criterion accepted by the food industry as a whole. It is widely believed that, as a form of social accountability, all companies should provide full compensation for any disease resulting from the company's products or practice. However, we also assume that companies do not necessarily compensate 100 percent, regardless of their level of responsibility. We are interested in examining the effects on their marketing strategy both with and without compensation.

\section{Interaction between Parents as Agents and a Food Company Marketing to Children}

\subsection{Derivation of Reaction Functions}

Note that we employ one representative food company as an example. Given the amount of television commercials $x$ offered by the food company at the beginning of period 1, parents as agents determine the optimum quantity of the independent demand $\widetilde{D}^{*}$, which differs from $D(x)$, which depends on the amount of television commercials. Meanwhile, the food company determines the optimum number of television commercials based on conjectures about $\widetilde{D}$ offered by parents. Both players react simultaneously to their opponent's decision with full information and without cooperating. Thus, these two players engage in a non-cooperative game that results in an equilibrium solution. The result of this game is thought to represent a Cournot-equilibrium solution, given the price constant in oligopoly (Kreps, 1990).

We present the objective function for children $U$ as

where

$$
U=\theta(\tau)\{u(\widetilde{D})-p \widetilde{D}-\delta \alpha(x)(1-\gamma) M \widetilde{D}\}+\{1-\theta(\tau)\}\{u(D(x))-p D(x)\}
$$

$p$ : price of food products (given)

$u$ ( ): willingness to pay (WTP) for food consumption $\left(u^{\prime}>0, u^{\prime \prime}<0\right)$

$M$ : compensation for diseases per consumption

$\delta \equiv \frac{1}{1+r} \quad r$ : interest rate $(0<r<1)$.

In equation (5), $\alpha(x)(1-\gamma) M \widetilde{D}$ accounts for the disease-related costs a consumer is expected to incur during period 2. Such expected costs are zero in case that no damage occurs, given by the probability $1-$ $\alpha(x)$. Similarly, we identify the profit function of the food company resulting from marketing to children as

$$
\pi=\theta(\tau)\{p \widetilde{D}-C(x)-\delta \alpha(x) \gamma M \widetilde{D}\}+\{1-\theta(\tau)\}\{p D(x)-C(x)-\delta \alpha(x) M D(x)\}
$$

In equation (6), $\{p \widetilde{D}-C(x)-\delta \alpha(x) \gamma M \widetilde{D}\}$ measures the profits the food company will obtain if children achieve a high level of consumer socialization and, thus, make rational economic decisions. Furthermore, this formula considers how much the company compensates as a result of the diseases for which it bears responsibility. Similarly, $\{p D(x)-C(x)-\delta \alpha(x) M D(x)\}$ reveals the profits the company will make under the same performance but taking into the account the amount of advertisements. As noted earlier, our main focus is the effect of a change in the amount of television commercials; thus, every cost irrelevant to $x$ is excluded from the components of profits in order to facilitate exposition.

We derive the first-order condition for each player's maximum from equations (5) and (6) as follows:

$$
\begin{gathered}
\frac{\partial U}{\partial \widetilde{D}}=\theta(\tau)\left\{u^{\prime}(\widetilde{D})-p-\delta \alpha(x)(1-\gamma) M\right\}=0 \\
\frac{\partial \pi}{\partial x}=-\theta(\tau) C^{\prime}(x)-\theta(\tau) \delta \alpha^{\prime}(x) \gamma M \widetilde{D}+\{1-\theta(\tau)\}\left\{p D^{\prime}(x)-C^{\prime}(x)-\delta M(\alpha(x) D(x))^{\prime}\right\}=0
\end{gathered}
$$

Differentiating equation (5) with respect to $\widetilde{D}$ and setting the result equal to zero gives the first-order condition for a maximum of children. Similar to the approach taken earlier, it is useful to confirm that $\widetilde{D}^{*}$, the optimal value of $\widetilde{D}$, shifts as the parameter $x$ changes. The locus of $\widetilde{D}^{*}$ shifting constitutes a reaction function for children. In turn, a similar procedure is applied to $x^{*}$, the optimal value of $x$, to yield a reaction function for the food company. Therefore, we find that equations (7) and (8) represent reaction functions for children and the food company, respectively, in space $\left(\widetilde{D}^{*}, x^{*}\right)$. At the intersection of both functions, unique equilibrium solutions $\left(\widetilde{D}^{* *}, x^{* *}\right)$ are determined. Algebraically, solving these two equations simultaneously with regard to $\widetilde{D}^{*}$ and $x^{*}$ assures the equilibrium profile. Note that hereafter we do not include these asterisks, which are shown here only for expositional convenience. 


\subsection{Interaction between Two Players}

Here we exhibit and prove some lemmas necessary for drawing conclusions.

Lemma 1: The reaction function for children always satisfies the following condition:

$$
\frac{d \widetilde{D}}{d x}=\frac{\delta \alpha^{\prime}(x)(1-\gamma) M}{u^{\prime \prime}(\widetilde{D})}<0
$$

Proof: The total differentiation in function (7) derives the inequality (9) while accounting for $\alpha^{\prime}(x)>$ 0 and $u^{\prime \prime}(\widetilde{D})<0$.

Inequality (9) indicates that the reaction function for children is always negatively sloping when $\widetilde{D}$ is on the vertical axis and $x$ is on the horizontal axis. Lemma 1 implies that parents as agents take the strategy independent of how consciously they are involved in consumer socialization, as the consumer's reaction function is unaffected by consumer socialization outcome $\theta(\tau)$. More precisely, the reaction function does not respond to an indicator of parental concern $\tau$, which varies for each individual. This finding is particularly meaningful in contrast with the food company's marketing strategy, as explained below.

Lemma 2: The reaction function for the food company is composed of the following two conditions:

$$
\begin{gathered}
\left\{\begin{array}{c}
\frac{d \widetilde{D}}{d x}>0 \quad \text { if } 0<\theta(\tau)<\theta(\bar{\tau}) \\
\frac{d \widetilde{D}}{d x} \leq 0 \quad \text { if } \theta(\bar{\tau}) \leq \theta(\tau)<1-\Omega
\end{array}\right. \\
\text { where } \theta(\bar{\tau}) \equiv \frac{p D^{\prime \prime}(x)-C^{\prime \prime}(x)-\delta M(\alpha D)^{\prime \prime}}{p D^{\prime \prime}(x)-\delta M(\alpha D)^{\prime \prime}-\delta \alpha^{\prime \prime} \gamma M \widetilde{D}} \\
\text { and } \Omega \equiv \frac{C^{\prime}(x)}{p D^{\prime}(x)-\delta M(\alpha D)^{\prime}}
\end{gathered}
$$

Proof: Rearranging equation (8) leads to the following expression:

$$
\widetilde{D}=\frac{p D^{\prime}-C^{\prime}-\delta M(\alpha D)^{\prime}}{\theta(\tau) \delta \alpha^{\prime} \gamma M}-\frac{p D^{\prime}-\delta M(\alpha D)^{\prime}}{\delta \alpha^{\prime} \gamma M}
$$

Rewriting a fundamental condition as $\widetilde{D}>0$ yields definition (12). Totally differentiating equation (8) with respect to $\widetilde{D}$ and $x$, followed by rearranging the result, would verify the shape of the food company's reaction function:

$$
\frac{d \widetilde{D}}{d x}=\frac{p D^{\prime \prime}-C^{\prime \prime}-\delta M(\alpha D)^{\prime \prime}}{\theta(\tau) \alpha^{\prime} \gamma M}-\frac{p D^{\prime \prime}-\delta M(\alpha D)^{\prime \prime}-\delta \alpha^{\prime \prime} \gamma M \widetilde{D}}{\alpha^{\prime} \gamma M}
$$

Setting the right-hand side of equation (14) equal to zero and rearranging the result leads to definition (11). When we use definitions (11) and (12) to determine whether the food company's reaction function is positively or negatively sloping, we acquire two conditions similar to those in equation (10).

Lemma 2 implies that variation of $\theta(\tau)$ significantly affects the food company's marketing strategy by inducing a change in the shape of its reaction function. As noted earlier, this finding is especially significant in contrast with the result of the children's reaction function. Food companies react to how consciously engaged parents are as consumer socialization agents, while parents play regardless of the level of parental concern for consumer socialization. This represents a main conclusion of this study.

\subsection{Property of Equilibrium}

To examine properties of the equilibrium, we superimpose the reaction function of one player on that of the other. Figures 1 to 3 show three cases depending on the relative slopes of both reaction functions. As explained by Lemmas 1 and 2, the children's reaction function is always negatively sloping, whereas the slope of the food company's reaction function depends on the value of $\theta(\tau)$. Figure 1 and 2 both illustrate cases with a stable equilibrium. Figure 3, however, represents an unstable equilibrium. The proceeding explanation clarifies why these cases differ in stability.

We investigate a series of adjustment processes by which we can confirm whether the equilibrium is stable. First, we consider the case in Figure 1. Suppose that parents' initial demand for food is at level $D_{0}$. The food company then sets $x_{0}$, the amount of the advertisement, making supply $S_{0}$ equal to demand $D_{0}$. In response to $x_{0}$, parents decide to reduce children's optimal consumption to $D_{1}$, and the process is repeated. This adjustment process 
ensures convergence to point $E$, and, therefore, Figure 1 is stable in equilibrium. Figure 2 depicts a case where both reaction functions are negatively sloping and the children's reaction function is flat relative to the food company's reaction function. This configuration shows that the adjustment process ultimately converges to equilibrium point $E$, regardless of the starting position (e.g., $D_{0}$ or $D_{1}$ ). For the case in Figure 3 , the process moves away from equilibrium point $E$ regardless of the starting position. Thus, Figure 3 represents an unstable equilibrium.

In the context of this study, the food company's marketing strategy is strongly affected by consumers' behavior, as the slope of the food company's reaction function varies with regard to changes in the value of $\theta(\tau)$. However, parents maximize their behavior regardless of how consciously they engage as consumer socialization agents. Furthermore, parents, as agents, react sensitively to a change in the amount of advertising by food companies. We find that food companies respond with great sensitivity to how deeply parents are engaged as consumer socialization agents.

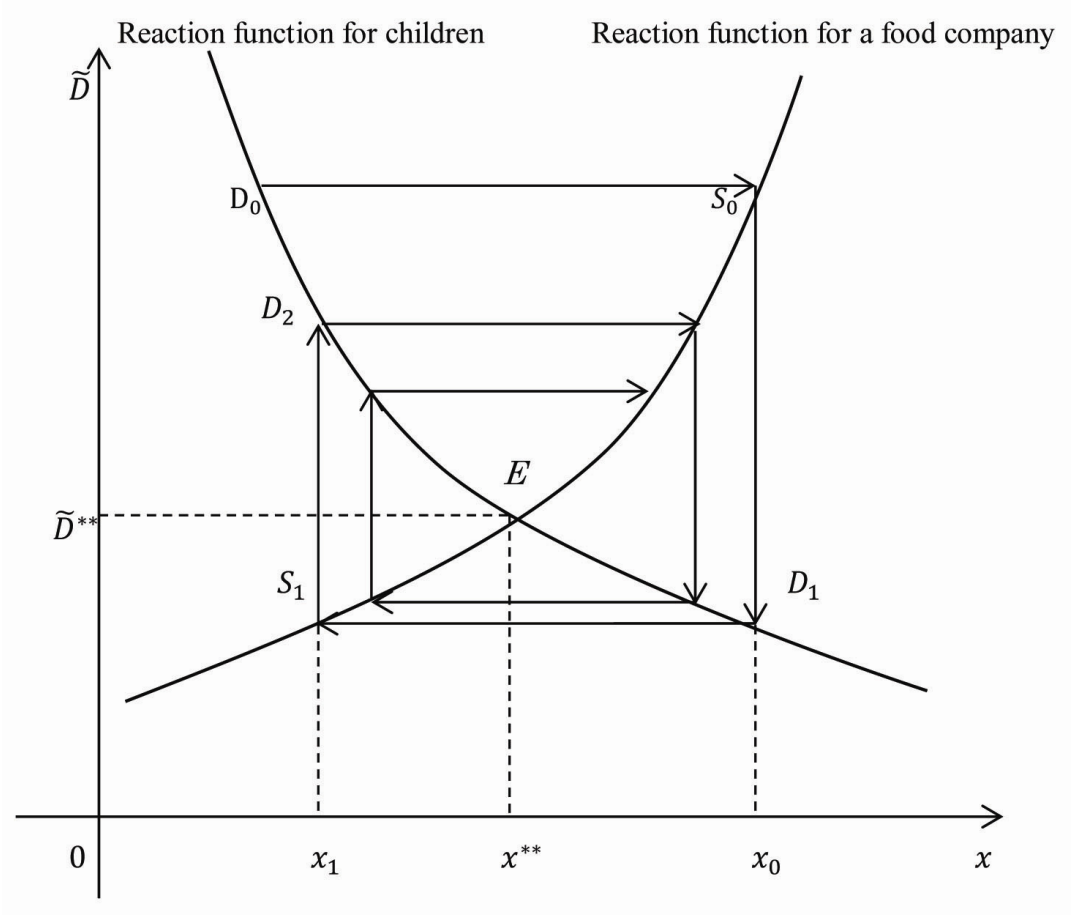

Figure 1. Stable equilibrium 


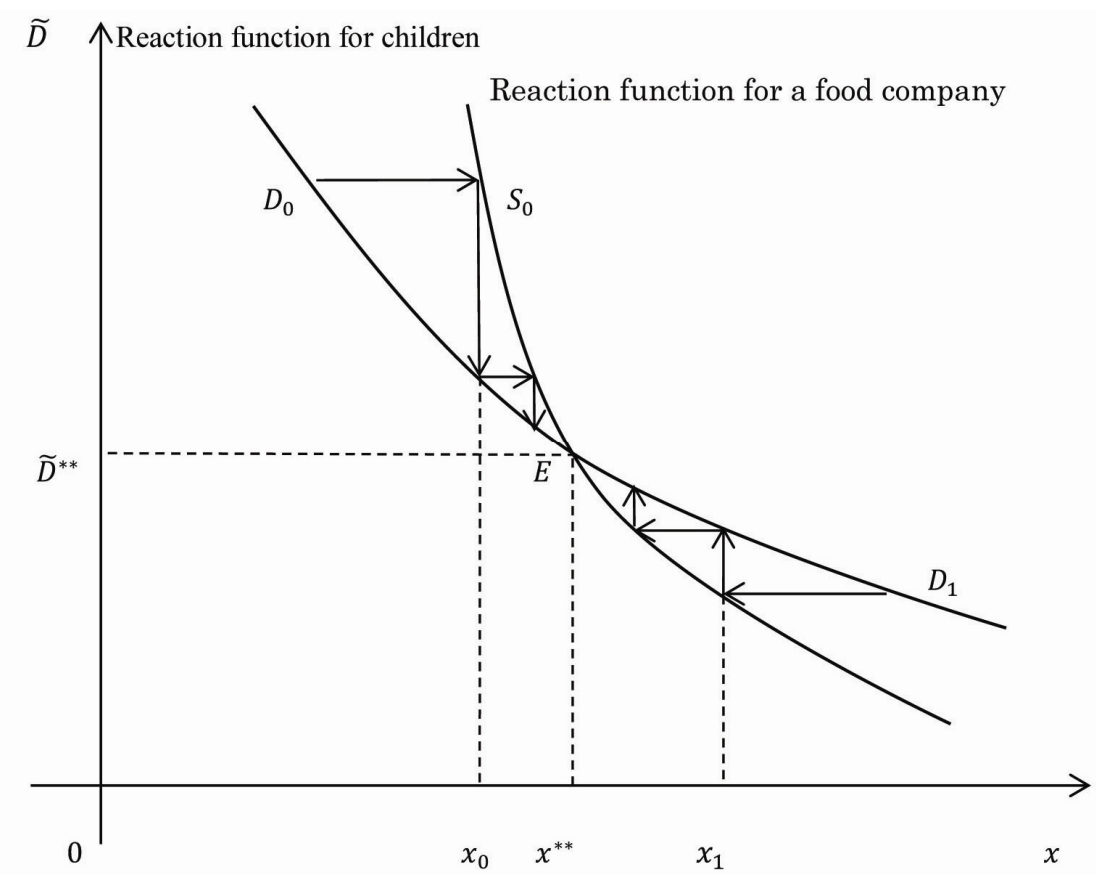

Figure 2. Stable equilibrium

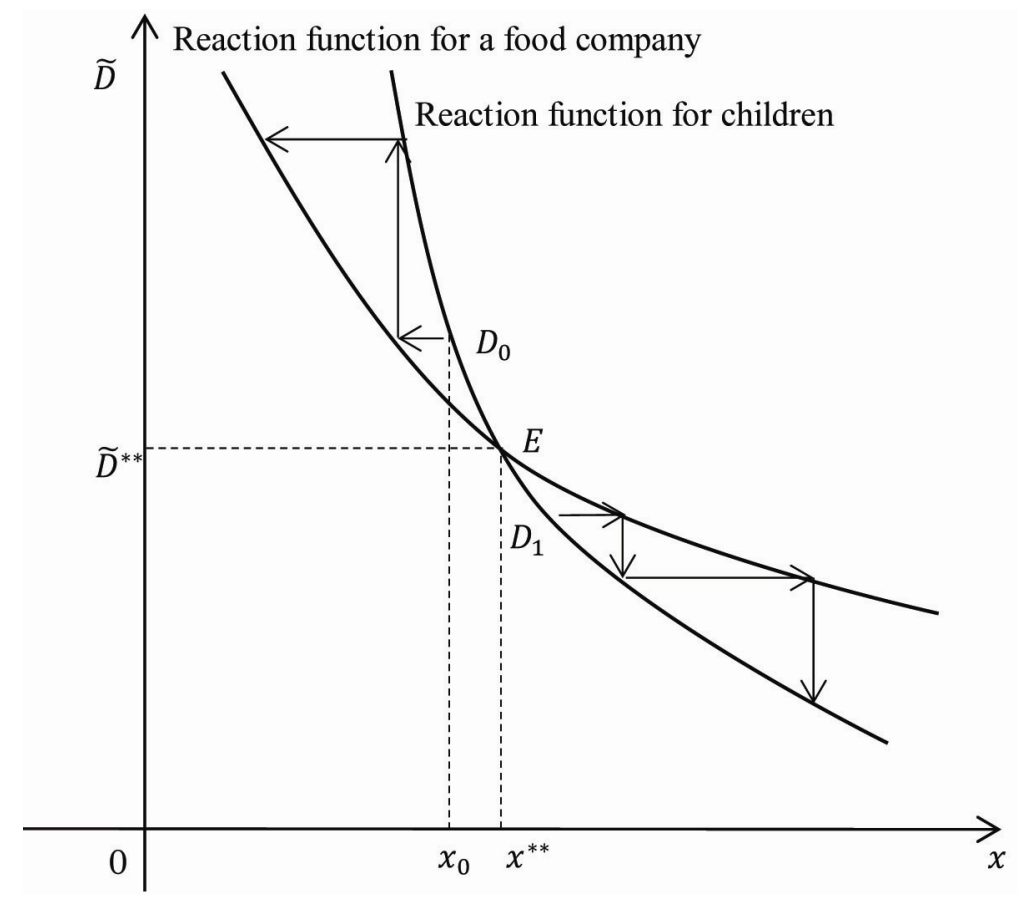

Figure 3. Untable equilibrium

\section{Conclusion}

We have examined an interaction between parents as agents of consumer socialization of children and food companies using microeconomic theory, in particular, game theory. We find that food companies are sensitive to the extent of parental concern for consumer socialization of children. Parents, on the other hand, behave independently of the significance of their concern for consumer socialization. We recognize that it is not necessarily optimal for parents to ignore food companies' marketing strategies. Parents as agents keenly react to the volume of advertisements food companies provide. This paper asserts that parents, as agents of consumer socialization of children, should consider how the volume of advertisements food companies supply is affected 
by the extent of parental concern for the socialization.

Our study has a number of defects and limitations. We focus solely only the amount of television commercials, without considering their content or quality. In light of recent marketing policy, we are certain that these factors are indeed crucial. Thus, such considerations remain to be taken up in future studies. Although we consider a two-period consumer time horizon, we focus exclusively on the behaviors at the beginning of the initial period. Following the work of Rose (1999), it would be useful to consider the entire developmental process of children in consumer socialization. Furthermore, to maximize a specific objective function, we implicitly presumed that it is preferable for children to make rational economic decisions rather than depend on food manufacturers' marketing strategies. Such an implicit assumption may be controversial from a marketing perspective. These issues will be addressed in our future research.

\section{Acknowledgements}

I would like to acknowledge Emiko Amano of Kanto Gakuin University for her intensive research that has continuously supported me in my study. I would like to thank Editage (www.editage.jp) for English language editing.

\section{References}

Ahmad, M., Sidin, S. M., \& Omar, N. A. (2011). A preliminary investigation of adolescents' perception of the role of internet in parent consumer socialization. The IUP Journal of Marketing Management, 10(3), 7-17.

Amano, E. (2014). A new approach to food and beverage marketing to children (in Japanese). Keizaikei: Quarterly Journal of Economics, 260, 117-132.

Bernhardt, A. M., Wilking, C., Adachi-Mejia, A. M., Bergamini, E., Marijnissen, J., \& Sargent, J. D. (2013). How television fast food marketing aimed at children compares with adult advertisements. PLoS ONE, 8(8), 1-6. http://dx.doi.org/10.1371/journal.pone.0072479

Buijzen, M. (2009). The effectiveness of parental communication in modifying the relation between food advertising and children's consumer behavior. British Journal of Developmental psychology, 27(Pt 1), 105-121. http://dx.doi.org/10.1348/026151008X334719

Carlson, L., \& Grossbart, S. (1988). Parental style and consumer socialization of children. Journal of Consumer Research, 15(1), 77-94. http://dx.doi.org/10.1086/209147

Carlson, L., Grossbart, S., \& Stuenkel, J. K. (1992). The role of parental socialization types on differential family communication patterns regarding consumption. Journal of Consumer Psychology, 1(1), 31-52. http://dx.doi.org/10.1016/S1057-7408(08)80044-7

Kreps, D. M. (1990). A course in microeconomic theory. New York, NY: Harvester Wheatsheaf.

Linn, S. (2004). Consuming kids: The hostile takeover of childhood. New York, NY: The New Press.

Mangleburg, T. F., \& Bristol, T. (1998). Socialization and adolescents' skepticism toward advertising. Journal of Advertising, 27(3), 11-21. http://dx.doi.org/10.1080/00913367.1998.10673559

McNeal, J. U. (1992). Kids as consumers: A handbook of marketing to children. New York, NY: Lexington Books.

Moschis, G. P. (1985). The role of family communication in consumer socialization of children and adolescents. Journal of Consumer Research, 11(4), 898-913. http://dx.doi.org/10.1086/209025

Özmete, E. (2009). Parent and adolescent interaction in television advertisements as consumer socialization agents. Education, 129(3), 372-381. Retrieved from http://eric.ed.gov/?id=EJ871577

Pomeranz, J. L. (2010). Television food marketing to children revisited: The Federal Trade Commission has the constitutional and statutory authority to regulate. Journal of Law, Medicine \& Ethics, 38(1), 98-116. http://dx.doi.org/10.1111/j.1748-720X.2010.00470.x

Rose, G. M. (1998). The influence of family communication patterns on parental reactions toward advertising: A cross-national examination. Journal of Advertising, 27(4), 71-84. http://dx.doi.org/10.1080/00913367.1998.10673570

Rose, G. M. (1999). Consumer socialization, parental style, and developmental timetables in the United States and Japan. Journal of Marketing, 63(3), 105-119. http://dx.doi.org/10.2307/1251778

Rose, G. M., Dalakas, V., \& Kropp, F. (2003). Consumer socialization and parental style across cultures: Findings from Australia, Greece, and India. Journal of Consumer psychology, 13(4), 366-376. 
http://dx.doi.org/10.1207/S15327663JCP1304_04

Scaglioni, S., Arrizza, C., Vecchi, F., \& Tedeschi, S. (2011). Determinants of children's eating behavior. American Journal of Clinical Nutrition, 94(suppl), 2006S-2011S. http://dx.doi.org/10.3945/ajcn.110.001685

Schor, J. B. (2004). Born to buy: The commercialized child and the new consumer culture. New York, NY: Scribner.

Ward, S. (1974). Consumer socialization. Journal of Consumer Research, 1(2), 1-14. http://dx.doi.org/10.1086/208584

Wilde, P. (2009). Self-regulation and the response to concerns about food and beverage marketing to children in the United States. Nutrition Reviews, 67(3), 155-166. http://dx.doi.org/10.1111/j.1753-4887.2009.00183.x

Wiman, A. R. (1983). Parental influence and children's responses to television advertising. Journal of Advertising, 12(1), 12-18. http://dx.doi.org/10.1080/00913367.1983.10672825

\section{Copyrights}

Copyright for this article is retained by the author(s), with first publication rights granted to the journal.

This is an open-access article distributed under the terms and conditions of the Creative Commons Attribution license (http://creativecommons.org/licenses/by/3.0/). 